Delft University of Technology

\title{
New opportunities with nanowires
}

Bakkers, E. P.A.M.; Hauge, H. I.T.; Li, A.; Assali, S.; Dijkstra, A.; Tucker, R.; Ren, Y.; Conesa-Boj, S.; Verheijen, M. A.

DOI

10.1109/PHOSST.2016.7548757

Publication date

2016

Document Version

Final published version

Published in

2016 IEEE Photonics Society Summer Topical Meeting Series, SUM 2016

\section{Citation (APA)}

Bakkers, E. P. A. M., Hauge, H. I. T., Li, A., Assali, S., Dijkstra, A., Tucker, R., Ren, Y., Conesa-Boj, S., \& Verheijen, M. A. (2016). New opportunities with nanowires. In 2016 IEEE Photonics Society Summer

Topical Meeting Series, SUM 2016 (pp. 124-125). [7548757] Institute of Electrical and Electronics Engineers (IEEE). https://doi.org/10.1109/PHOSST.2016.7548757

Important note

To cite this publication, please use the final published version (if applicable).

Please check the document version above.

\section{Copyright}

Other than for strictly personal use, it is not permitted to download, forward or distribute the text or part of it, without the consent of the author(s) and/or copyright holder(s), unless the work is under an open content license such as Creative Commons.

\section{Takedown policy}

Please contact us and provide details if you believe this document breaches copyrights.

We will remove access to the work immediately and investigate your claim. 


\title{
New Opportunities with Nanowires
}

\author{
E.P.A.M. Bakkers ${ }^{1,2}$ H. I. T. Hauge ${ }^{1}$, A. Li $^{1}$, S. Assali ${ }^{1}$, A. Dijkstra ${ }^{1}$, R. Tucker ${ }^{1,3}$, Y. Ren ${ }^{1}$, \\ S. Conesa-Boj ${ }^{2}$ and M. A. Verheijen ${ }^{1,4}$ \\ ${ }^{1}$ Eindhoven University of Technology, 5600 MB Eindhoven, the Netherlands \\ ${ }^{2}$ Delft University of Technology, 2600 GA Delft, the Netherlands \\ ${ }^{3}$ University of Alberta, National Institute for Nanotechnology, Canada \\ ${ }^{4}$ Philips Innovation Services, 5656 AE, Eindhoven, the Netherlands
}

Light emission from $\mathrm{Si}$, would allow integration of electronic and optical functionality in the main electronics platform technology, but this has been impossible due to the indirect band gap of Si. In this talk I will discuss 2 different approaches, using unique properties of nanowires, to realize light emission from Si-based compounds.

In the first route we focus on the fabrication of defect-free GeSn compounds. GeSn has been shown to exhibit a direct band gap at Sn concentrations above $12.5 \%$ in the infrared part of the spectrum (around $0.5 \mathrm{eV}$ ). ${ }^{1}$ However, in bulk layers the strain between the Ge and the GeSn layer is released by the introduction of defects near the interface affecting the optical properties of the layer. In the nanowire geometry the lattice strain can be effectively relieved in the radial direction, which is exploited to grow $\mathrm{Ge} / \mathrm{GeSn}$ core shell nanowires with high (13\%) Sn content. The wires are grown by the Vapor-Liquid-Solid (VLS) growth mechanism in an Metal-Organic Vapor Phase Epitaxy (MOVPE) system at low temperatures. The core/shell nanowires are free of dislocations and therefore show a very high photoluminescene internal quantum yield of around $10 \%$ at room temperature. In this talk the growth mechanism is discussed, the structural properties are investigated by Electron Microscopy and Atom Probe Tomography and the temperature dependent optical properties are studied.

In the second route we concentrate on $\mathrm{Si}$ and $\mathrm{Ge}$ with a different crystal structure. It has been predicted that $\mathrm{SiGe}$ alloys with the hexagonal $(2 \mathrm{H})$ crystal structure have a direct band gap. It has been shown that by using the VLS nanowire growth mechanism it is possible to fabricate III-V semiconductors, which normally crystallize in the cubic phase, can now been grown with a $2 \mathrm{H}$ crystal structure. ${ }^{2}$ This system has the unique ability to control and switch the crystal structure with a precision at the atomic monolayer level. ${ }^{3}$ Here, we employ crystal structure transfer, in which we use wurtzite $\mathrm{GaP}$ as a template to epitaxially grow $\mathrm{SiGe}$ compounds with the hexagonal crystal structure (see figure 1). ${ }^{4}$ We show that with this method we can grow defect free hexagonal SiGe shells and branches with tunable $\mathrm{Ge}$ concentration. The structural and optical properties of these new crystal phases will be discussed.

We believe that these new 3-dimensional epitaxial nanostructures have great potential to integrate optical functionality in Si technology.

\section{References}

1. Wirths, S. et al. Lasing in direct-bandgap GeSn alloy grown on Si. Nat. Photonics $\mathbf{9}$, 88-92 (2015).

2. Assali, S. et al. Direct band gap wurtzite gallium phosphide nanowires. Nano Lett. 13, 1559-1563 (2013).

3. Assali, S. et al. Exploring Crystal Phase Switching in GaP Nanowires, Nano Letters 15, (2015(, DOI: 10.1021/acs.nanolett.5b03484

4. Hauge, H.I.T. et al. Hexagonal Si realized, Nano Letters 15, (2015), DOI: 10.1021/acs.nanolett.5b01939 


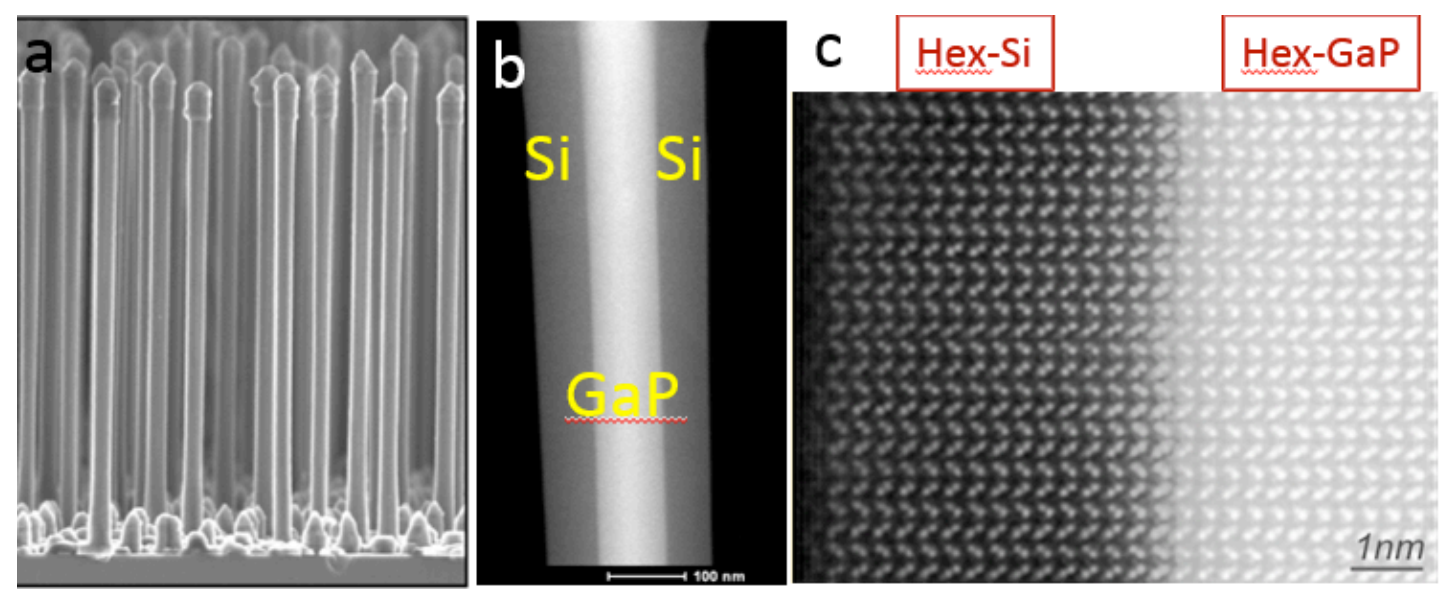

Fig. 1: Transfer of the crystal structure from a wurtzite GaP core wire into a Hex-Si shell. (a) SEM image of GaP/Si core/shell NWs, (b) TEM image of a Hex-GaP/Si core/shell NW, (c) High-resolution TEM image of GaP/Si interface confirming the hexagonal Si crystal structure. ${ }^{4}$

a

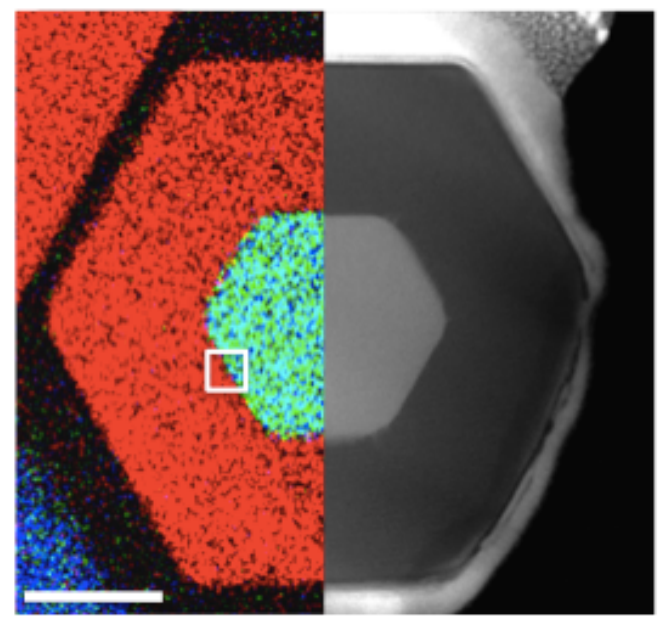

D

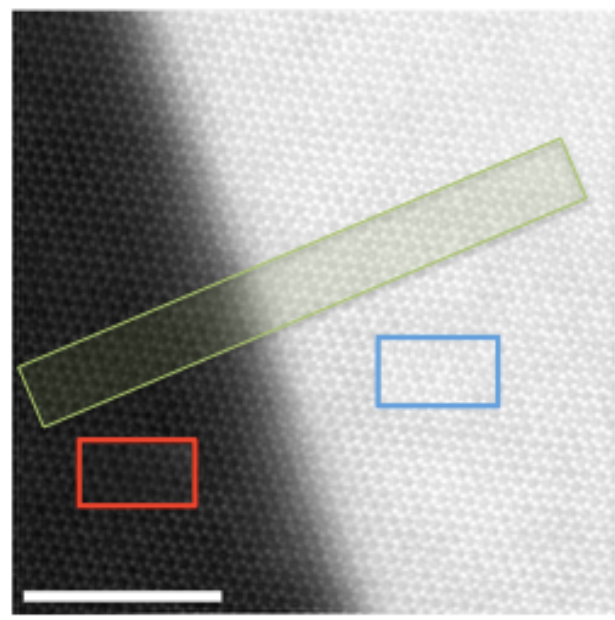

Fig. 2 : (a) cross sectional TEM image of a hexagonal GaP/Si core/shell nanowire illustrating the conformal epitxial growth, (b) High-resolution TEM image of the GaP/Si interface substantiating the defect-free hexagonal Si crystal structure. ${ }^{4}$ 